\title{
Stress intensity factors for multiple cracks in thick-walled cylinder
}

\author{
Krunal G. Girase ${ }^{1}$, Navneet K. Patil ${ }^{1}$, Dinesh Shinde ${ }^{2}$, Kanak Kalita ${ }^{2 *}$ \\ ${ }^{1}$ Department of Mechanical Engineering SSBT's COET \\ ${ }^{2}$ Department of Mechanical Engineering MPSTME, SVKM's NMIMS Shirpur \\ *Corresponding author E-mail:kanak.kalita@nmims.edu
}

Copyright $(\odot$ 2015Krunal G. Girase et al. This is an open access article distributed under the Creative Commons Attribution License, which permits unrestricted use, distribution, and reproduction in any medium, provided the original work is properly cited.

\begin{abstract}
The stress intensity factor (SIF) is the linear elastic fracture mechanics parameter that relates remote load, crack size and structural geometry. It predicts very accurately the stress state. In this work, cylinders with multiple cracks are considered. The following parameters are varied during the analysis of the cylinders: the number of cracks, (the variation in number of cracks ultimately led to a variation in the inter-crack spacing), the crack length to cylinder thickness ratio $(\mathrm{a} / \mathrm{t})$, the diameter ratio of the cylinders. Very good agreement between the finite element stresses and the theoretical stresses is seen.
\end{abstract}

Keywords: Ansys; Crack, FEM; Pressure Vessel; SIF.

\section{Introduction}

Thick walled cylinders are generally designed for industrial purposes to work safely at a definite pressure and temperature which is called as the design pressure and design temperature. Any cylinder inappropriately designed such that it cannot handle high pressure is considered as a potential safety hazard. There are several agencies worldwide that design and certify the pressure vessels. They lay down design codes like the American Society of Mechanical Engineers' Boiler and Pressure Vessel Code in North America [1], the Pressure Equipment Directive of the European Union (PED) [2], Japanese Indus- trial Standard (JIS) [3], CSA B51 in Canada [4], AS1210 in Australia [5] and other international standards like Lloyd's Germanischer Lloyd [6], Det Norske Veritas [7], Stoomwezen [8] etc.

In a thick-walled pressure vessel, sites for crack initiation are either caused by design features such as notches, or by accident, e.g., flaws due to manufacturing process or handling. Cracks may also be formed in pressure vessels subjected to be extreme loading conditions [9]. The length of a crack in a pressure vessel may increase due to the application of repeated loads or due to a combination of loads and environmental attack. As its length increases, so does the stress concentration prompted by it [10]. Due to the presence of the crack, the residual strength of the pressure vessel declines gradually with increasing crack size until it becomes so small that the pressure vessel cannot endure high pressures. Even if the cylinder is not subjected to very high pressures, the crack will continue to grow until the residual strength becomes so low that fracture occurs under normal service pressure [10].

Cracks may result in leakage or rupture failures. Failure, when dealing with pressure vessels, especially those subjected to very high pressures, can present major safety issues [11]. The potential dangerous results of leaking pressure vessels include suffocation, poisoning, and even explosion. Rupture failures, which may result from leaking pressure vessels, maybeeven more catastrophic. Such failures may cause large amounts of damage to property. For instance, the Mihama nuclear power plant accident which occurred on 9th August, 2004 caused the death of four (4) people on the spot and seven (7) others were seriously injured. A pipe carrying pressurized water suddenly ruptured and caused the accident [12]. Service failure of pressure vessels causes very huge financial losses, especially where such vessels are being used in aero planes, as reactor vessels, storage tanks or in a power plant [10].

By 1992, the stress intensity factors data available consisted of as much as 400 values of KIP (the K due to internal pressure, for diverse crack arrays and for an extensive range of crack lengths), as well as in excess of 200 values of KIA 
(the negative $\mathrm{K}$ due to the compressive residual stress field prompted by the auto frettage process for various configurations of crack arrays and different levels of auto frettage) [13].

In multiple cracked cylinders, the stress intensity factors were found to reduce to MK, where $\mathrm{M}$ is a function of crack length, geometry of cylinder and number of cracks. Approximate results for a pipe having diameter ratio of 2 and containing 40 eqi-spaced cracks have been presented. Multiple cracks have significant effect on the stress intensity [14]. Clark and Morton [15] proposed another procedure for estimating SIF in thick-wall pressure vessels. These pressure vessels were subjected to internal pressure and had multiple cracks. The procedure was simple and easy to apply. Despite the unjustified mathematical assumptions the method was in good approximation was the previous literature.

The idea of load relief factor was applied to calculate SIF for a plane with multiple cracks and axisymmetric body [16]. To establish the soundness of the method it was compared with already accepted results from literature. The results were well within the data obtained from a more exact formulation.

\section{Preliminary notes}

\subsection{Stresses in thick-walled cylinders}

Stresses in thick-walled cylinders are classified according to the directions in which they act. There are three classes of stresses, which are found in a loaded cylinder and these are;

Hoop or tangential stress, $\sigma_{\theta}$

Radial stress, $\sigma_{\mathrm{r}}$

Longitudinal/axial stress, $\sigma_{1}$

Any of these stresses at a particular point $(\mathrm{R})$ in a cylinder can be calculated using the Lame's equation i.e.

$\sigma_{\theta}=A_{i}+\frac{A_{2}}{R^{2}}(1)$

$\sigma_{\mathrm{r}}=\mathrm{A}_{1}-\frac{\mathrm{A}_{2}}{\mathrm{R}^{2}}(2)$

$\sigma_{1}=\mathrm{A}_{1}$

Where,

$A_{1}=\frac{P_{i} R_{i}^{2}-P_{o} R_{o}^{2}}{R_{o}^{2}-R_{i}^{2}}$

$A_{2}=\frac{\left(P_{i}-P_{o}\right) R_{o}^{2} R_{i}^{2}}{R_{o}^{2}-R_{i}^{2}}$

$\mathrm{P}_{\mathrm{i}}$ is the internal pressure acting on the cylinder

$\mathrm{P}_{\mathrm{o}}$ is the external pressure acting on the cylinder

$R_{i}$ is the inner radius of the cylinder

$R_{o}$ is the outer radius of the cylinder

\subsection{Stress concentration factor (SCF)}

SCF is the ratio of the maximum stress at the crack tip to the corresponding nominal stress that existed at the location of the crack tip before the formation of the crack. That is;

$\mathrm{K}_{\mathrm{f}}=\frac{\sigma_{\max }}{\sigma_{\mathrm{o}}}$

The value of the SCF depends on the dimensions of the crack. As a design engineer it is always expected to reduce stress concentrations as much as possible to negate fatigue problems.

\subsection{Stress intensity factor (SIF)}

SIF in linear elastic fracture mechanics is defined as a parameter that relates remote load, crack size and structural geometry. It forecasts very precisely the stress state in the vicinity of a crack caused by a remote load or residual stress. The crack initiation life is greatly at the mercy of the stress concentration factor $\mathrm{K}_{\mathrm{f}}$ value. The crack initiation period is followed by the fatigue crack growth period. The SCF is generally not considered as an accurate measure of the severity of the stress distribution in vicinity of the crack tip [17]. 
The difference between a notch and a crack can be demonstrated by considering an elliptical hole [18]. In an infinite plate under tension, SCF is given by $[19,17]$

$\mathrm{k}_{\mathrm{f}}=1+2 \sqrt{\frac{\mathrm{a}_{1}}{\rho}}$

$\rho=\frac{b_{1}^{2}}{a_{1}}$

Where;

$a_{1}$ is the major semi-axis of the elliptical hole

$\mathrm{b}_{1}$ is the minor semi-axis of the elliptical hole

$\rho$ is the tip radius of the elliptical hole

A crack is a notch with zero tip radius, SCF would become infinite, and this would be true for any crack length. The SIF is therefore a better concept of describing the severity of the stress distribution around the crack tip. K can be expressed as;

$\mathrm{K}=\lambda \rho \sqrt{\pi \mathrm{a}}$

Where $\sigma$ is the remote loading stress, ' $\mathrm{a}$ ' is the crack length and $\lambda$ is a dimensionless factor which depends on the shape and dimensions of the specimen. The important feature therefore is that the SIF fully determines the stress field in vicinity of the crack tip.

\section{Methodology}

The Ansys10 Finite Element Analysis software was used in this study. This software was used to obtain the nodal forces at the crack tip as well as the displacements in the vicinity of the crack tip. These two parameters were then used in the modified virtual crack closure technique to obtain the stress intensity factors. Cylinders with single cracks as well as those with multiple cracks were considered. The following parameters were varied during the analysis of the cylinders:

- The number of cracks. (The variation in number of cracks ultimately yielded to a variation in the inter-crackr spacing)

- The crack length to cylinder thickness ratio $(\mathrm{a} / \mathrm{t})$.

- The diameter ratio of the cylinders.

For cylinders with an even number of cracks, due to symmetry, the analysis was done by considering a quadrant of the cylinder. For those with an odd number of cracks, again due to symmetry, the analysis was done by considering a half of the cylinder. Fig. 1 show the model that was used in the analysis of a cylinder with three cracks whereas Fig. 2 shows the part which was ignored in order to take advantage of the symmetry of the cylinder. For the sake of clarity, the sizes of the cracks have been exaggerated.

The procedure for analyzing the cylinders with an even number of cracks is similar to that of analyzing those with an odd number of cracks. In both cases, half crack at the line of symmetry of the model was used for the analysis. The material properties were chosen as $\mathrm{E}=210 \mathrm{GPa}$ and $v=0.3$. Solid-Tet-10node-187 elements were used in meshing the models. As an example, the model for a cylinder with six cracks is used to explain how the analysis was done.

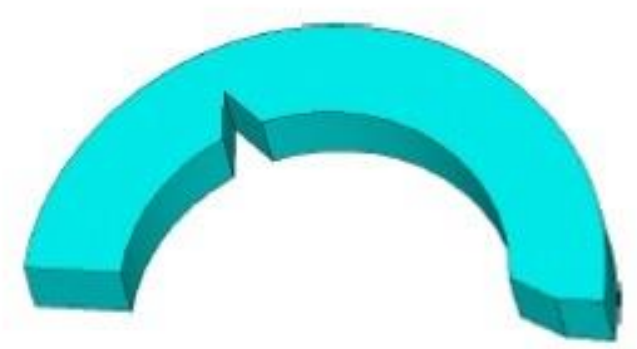

Fig. 1: 3-D Model for a Cylinder with 3 Cracks 
The whole model was freely meshed using the selected elements. Mesh refinement was done for the whole model by a factor improvement of three. Finally mesh refinement was done at the crack tip by a factor improvement of two. This is illustrated in Fig 3.

All the areas in the model were numbered so as to facilitate accurate application of the boundary conditions. Static displacement conditions were applied on both lines of symmetry of the model so as to prevent the rotation of the model after the application of internal pressure. Pressure was applied on the internal surfaces of the cylinder and also on the crack faces making sure that yielding did not occur at any point in the cylinder. Plain strain conditions were assumed for the model which was remote from the cylinder ends. The precondition conjugate solver was then used to obtain the finite-element solution for the model.

The node numbering was activated and nodal forces were obtained at five consecutive nodes at the crack tip. Displacements were also obtained at five consecutive nodes near the crack tip and they were used together with the previously obtained nodal forces to calculate the SIF. The results obtained for the multiple cracked cylinders were compared with those of Shu [20].

\section{Results and discussion}

\subsection{Model validation}

The radial, hoop and axial stresses obtained from the finite-element model were compared with their corresponding theoretical stresses obtained using the Lame's equations, i.e. equations 1 and 2. Fig. 4 shows the comparison of these stresses for a flawless cylinder with a thickness ratio, $\mathrm{Y}=1.5$.

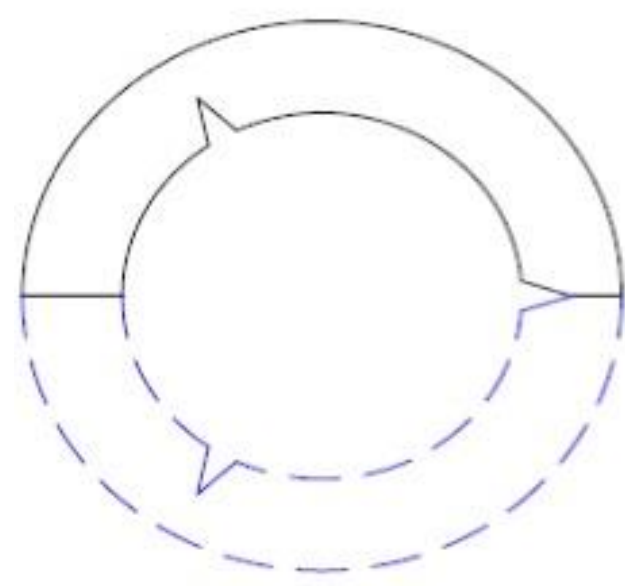

Fig. 2: Front View of a Model for a Cylinder with 3 Cracks

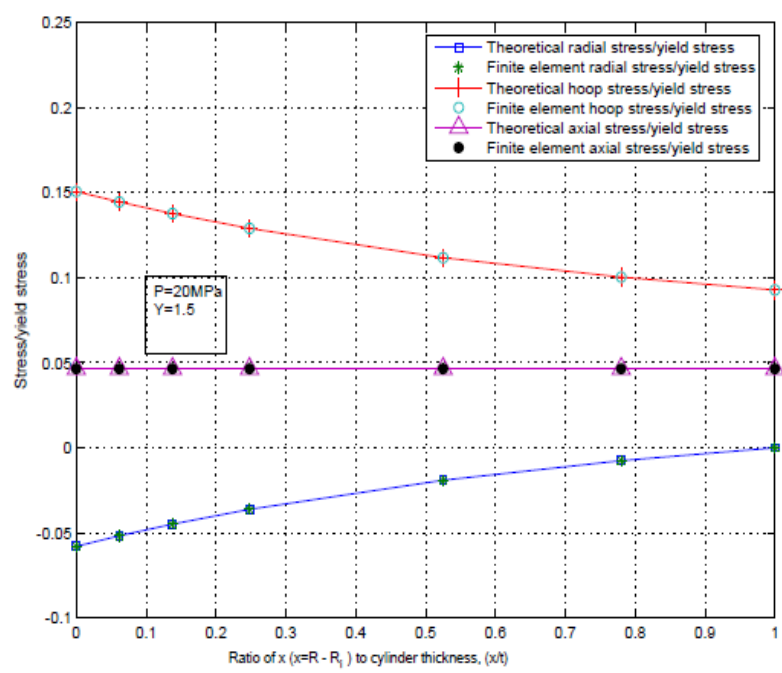

Fig. 4: Theoretical Versus Finite Element Stresses

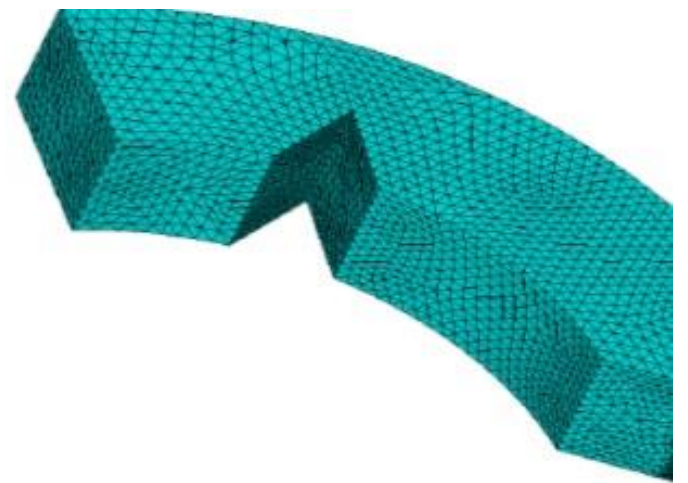

Fig. 3: Mesh Refinement at Crack Tip with Boundary Conditions

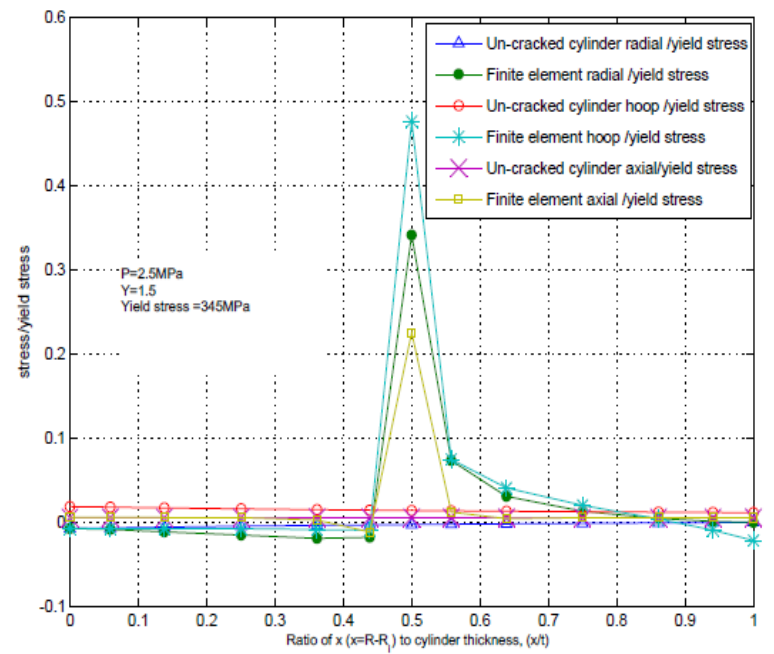

Fig. 5: A Cracked Cylinder Finite Element Stresses Versus an UnCracked Cylinder Theoretical Stresses 


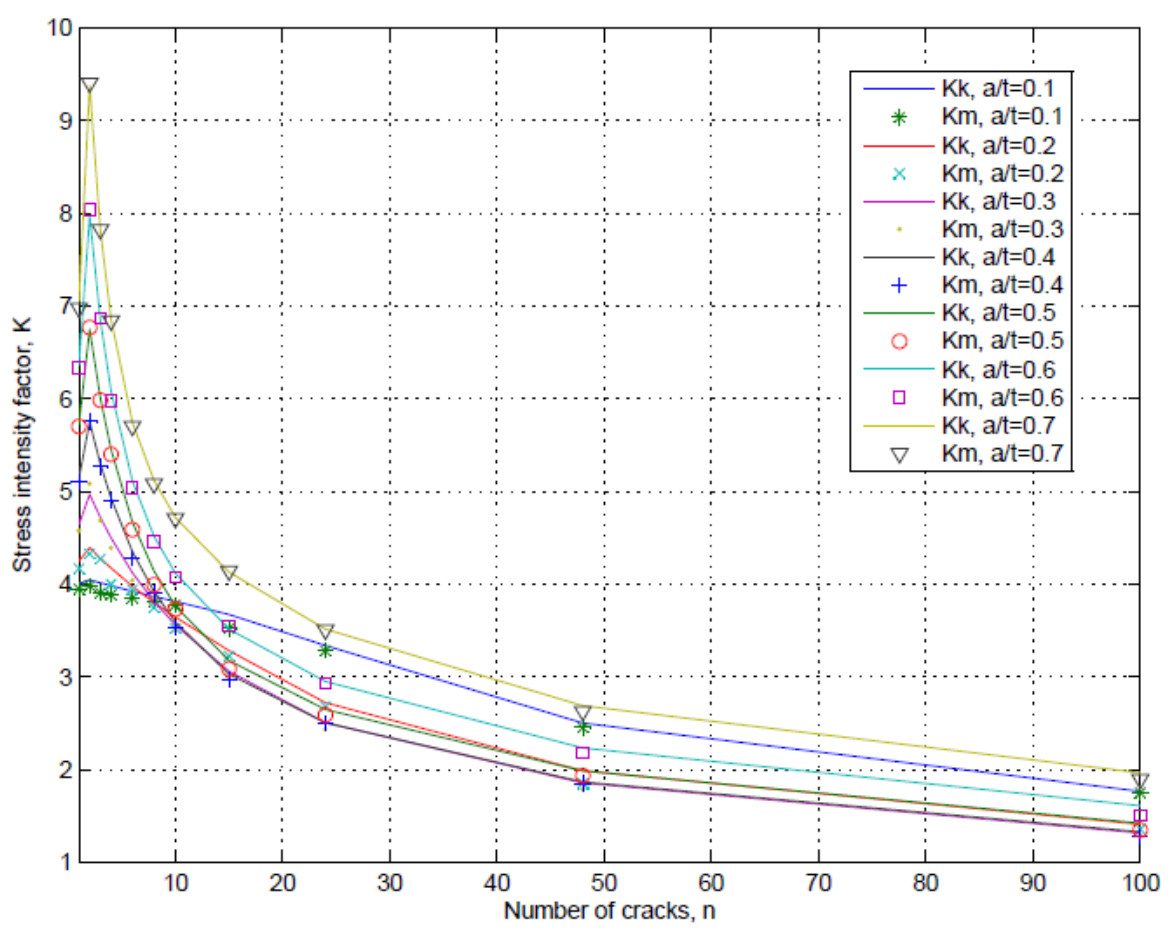

Fig. 6: K Values for a Thick-Walled Cylinder with Multiple Cracks and $\mathrm{Y}=1.5$

From the graph, it was evident that there was very good agreement between the finite element stresses and the theoretical stresses. Both the hoop stress and the radial stress (which has a negative value since it is compressive in nature) were found to decrease with increasing radius of the cylinder. This was because the cylinder considered was subjected to internal pressure only. The axial stresses were found to have a constant value throughout the cylinder thickness, and this was the pressure required to counteract the influence of the internal pressure on the cylinder ends. Since there was a good agreement between the flawless cylinder's finite element stresses and theoretical stresses, it was now possible to confidently use the Ansys10 Finite Element Analysis Software to analyze models of cracked thickwalled cylinders.

Fig. 5 shows the comparison of the finite element stresses with those obtained using the Lame's equations for a cylinder with a thickness ratio of 1.5 having a crack whose length extended up to half the thickness of the cylinder. From the Fig., it is clear that the presence of the crack introduced a region of stress concentration at the crack tip where the finite element stresses were very high. The hoop stress at the crack tip was found to be higher than the other stresses at the crack tip and this was due to the fact that the pressure loading on both crack faces was acting in the circumferential direction. This also proved that the cylinder under consideration was more likely to fail in tensile mode and thus showed why the mode, I stress intensity factor is of greater interest than the other stress intensity factors.

\subsection{Stress intensity factors for cylinders with multiple cracks}

The SIF were calculated for $1_{-} \mathrm{n}_{-} 100,1.5 \_\mathrm{Y}_{-} 2: 5$ and $0.1 \_\mathrm{a} / \mathrm{t} \_$0:7. The values obtained were compared with those in literature [21]. The maximum value of $\mathrm{K}$ was found to occur when $\mathrm{n}=2$. As the number of cracks increase, the value of $\mathrm{K}$ decreases. $\mathrm{K}$ also increases with a/t but decreases as $\mathrm{Y}$ increases. Fig. 6 to 7 show the variation of $\mathrm{K}$ with $\mathrm{n}$ for various a/t ratios when $\mathrm{Y}$ is constant. For the sake of clarity, graphs of the variation of $\mathrm{K}$ with $\mathrm{n}$ at various, a/t and $\mathrm{Y}$ ratios are also presented in Fig. 8 to 13. The actual values of $\mathrm{K}$ are presented in Fig. 6 to Fig. 13. From Fig. 6, it was evident that for any a/t ratio, the highest value of $\mathrm{Km}$ occurred when $\mathrm{n}=2$. This was in agreement with what had been reported earlier in literature that the two diametrically opposed cracks 'assist' each other in weakening the cylinder [20]. It was also evident from the Fig. that $\mathrm{Km}$ decreased as $\mathrm{n}$ increased from 2 . This was attributed to the concept of load relief whereby the crack opening forces due to the applied pressure were shared by the increasing number of cracks. For $\mathrm{n}<10$, the stress intensity factor was found to increase with $\mathrm{a} / \mathrm{t}$ and this was mainly due to the fact that, as a/t increased, the remaining cylinder thickness in front of the crack tip was decreasing and the gap between the two pressurized crack faces at the crack tip was reducing. The cracks also being far apart meant there was no interaction with the forces acting on neighboring cracks.

For $n>10$, the value of $\mathrm{Km}$ was found to generally decrease with a decreasing value of $\mathrm{a} / \mathrm{t}$ except for $\mathrm{a} / \mathrm{t}=0.1 \mathrm{where}$ the values of $\mathrm{Km}$ are nearly equal to the values of $\mathrm{Km}$ when $\mathrm{a} / \mathrm{t}=0.7$. The high values of $\mathrm{Km}$ when $\mathrm{a} / \mathrm{t}=0.1$ were attributed to the high hoop stress near the inner surface of the cylinder. The values of Km in Fig. 6 were in good agreement with those obtained from literature. 

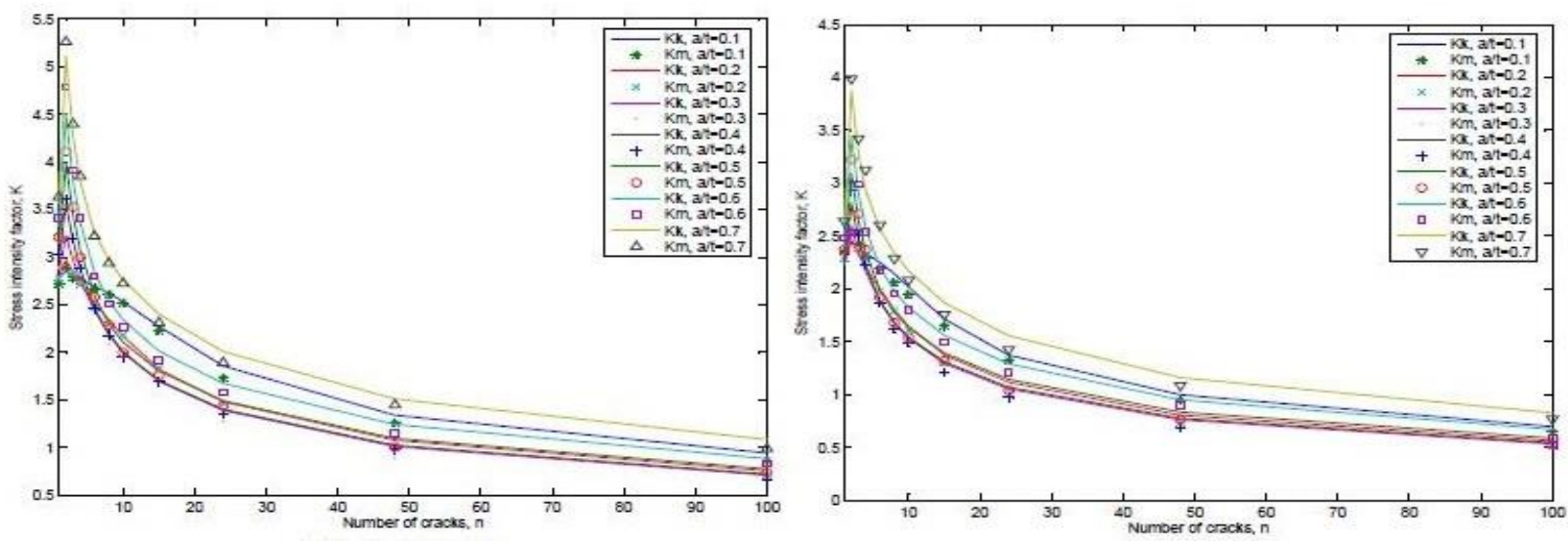

$\begin{array}{ll}\text { (a) } \mathrm{K} \text { values } \mathrm{Y}=2.0 & \text { (b) } \mathrm{K} \text { values } \mathrm{Y}=2.5\end{array}$

Fig. 7: K Values for Cylinders with $\mathrm{Y}=2.0$ and $\mathrm{Y}=2.5$

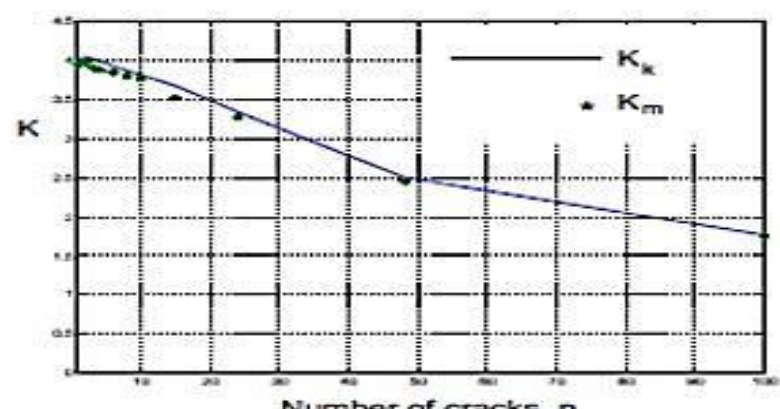

Number of cracks, $n$

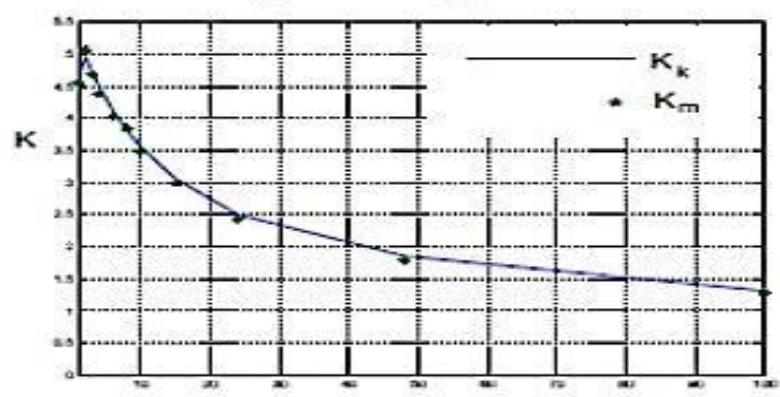

Number of cracks, $n$

(c) $Y=1.5, \mathrm{a} / \mathrm{t}=0.3$

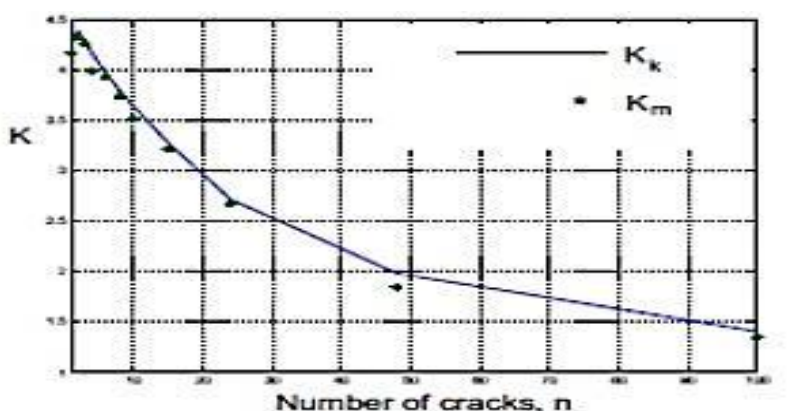

(b) $Y=1.5, a / t=0.2$

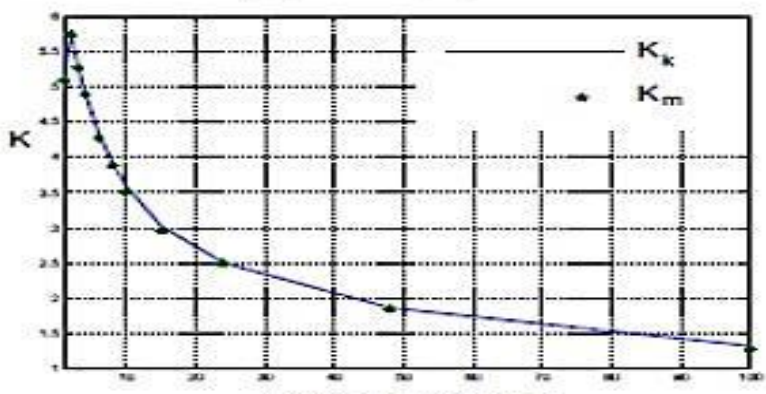

Number of cracks, $n$

(d) $Y=1.5, a / t=0.4$

Fig. 8: $\mathrm{K}$ Values for $\mathrm{Y}=1.5, \mathrm{~A} / \mathrm{T}=0.1$ to $\mathrm{Y}=1.5, \mathrm{~A} / \mathrm{T}=0.4$

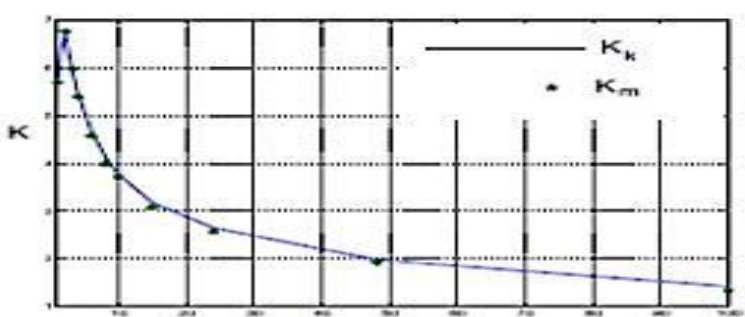

Number of cracks, $n$

(a) $Y-1.5, \mathrm{~s} / \mathrm{t}=0.5$

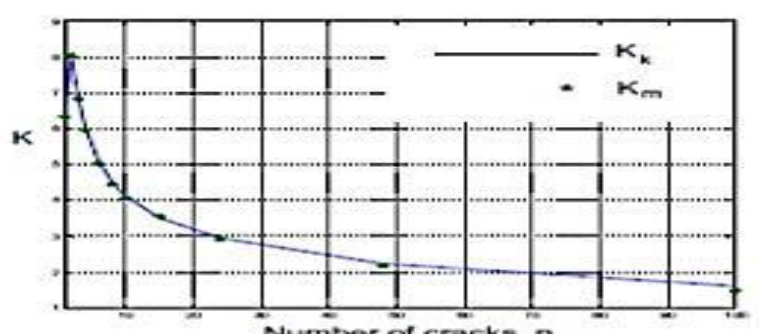

(b) $Y-1.5, a / t=0.6$

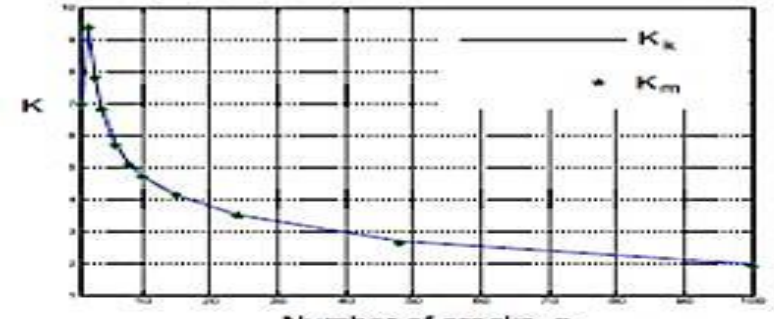

Number of cracks. $n$
(c) $Y=1.5,2 / t=0.7$

Fig. 9: $K$ Values for $Y=1.5, A / T=0.5$ to $Y=1.5, A / T=0.7$ 

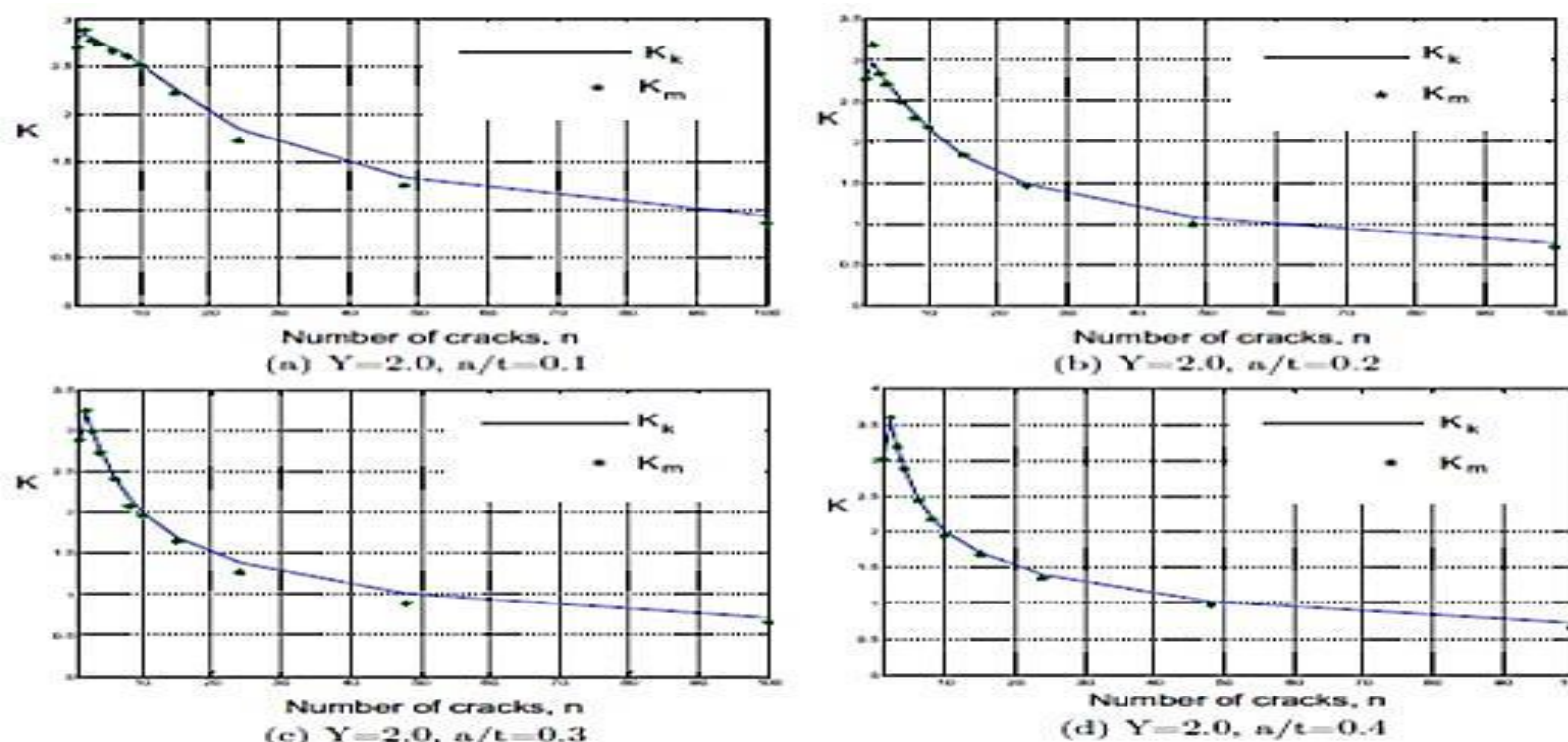

Numbor of cracks. $n$
(b) $Y=2,0,0 / \varepsilon=0.2$

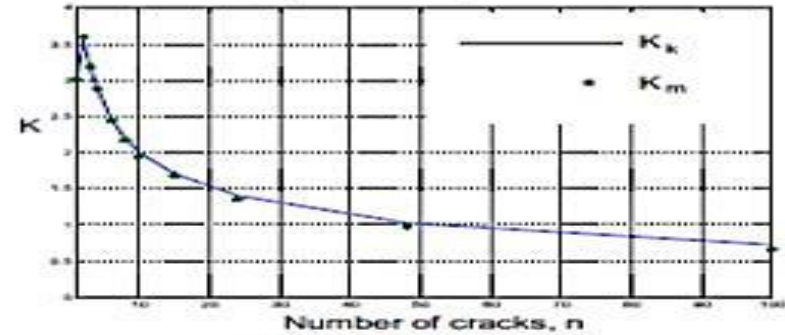

(d) $Y=2.0, n / t=0.4$

Fig. 10: $K$ Values for $Y=2.0, A / T=0.1$ to $Y=2.0, A / T=0.4$
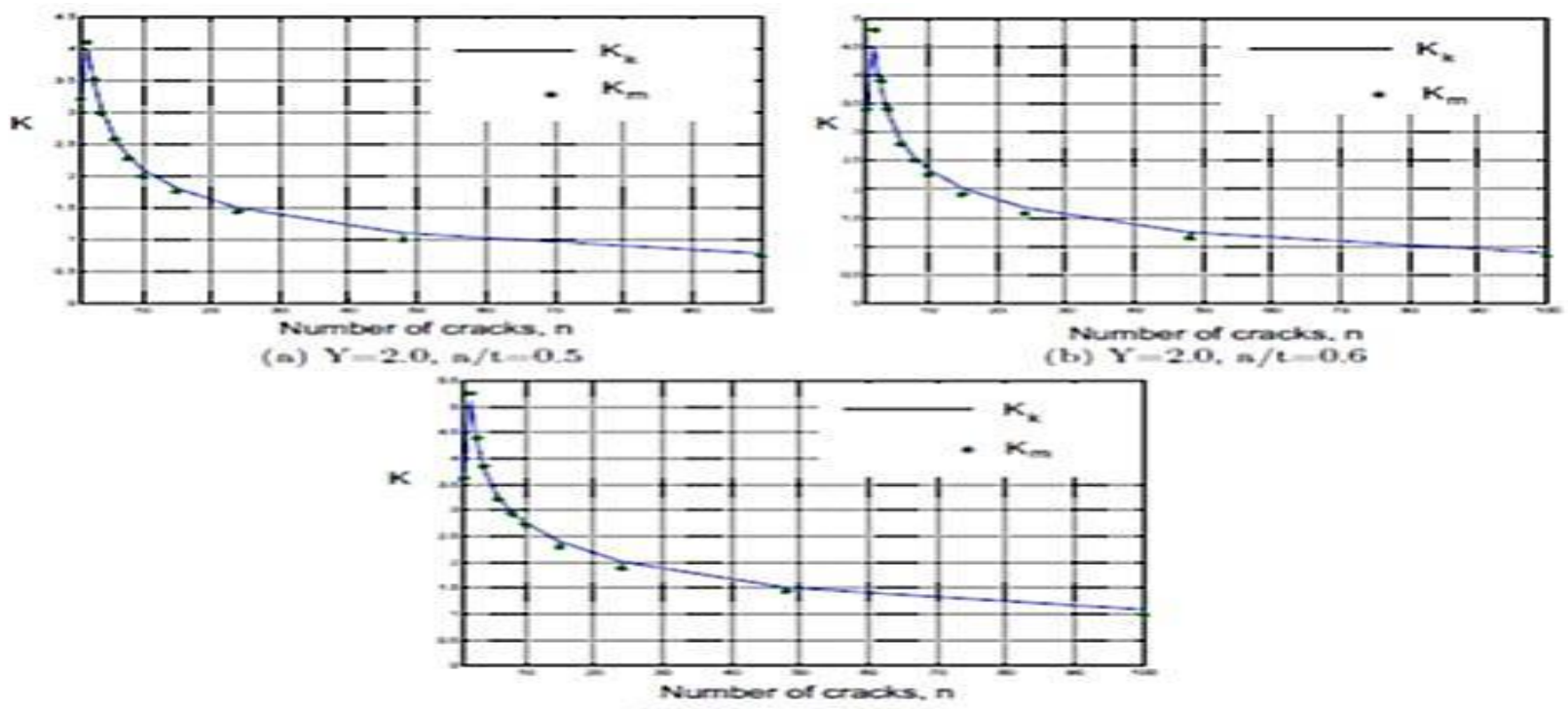

(c) $Y=20, m /=0.7$

Fig. 11: $K$ Values for $Y=2.0, A / T=0.5$ to $Y=2.0, A / T=0.7$

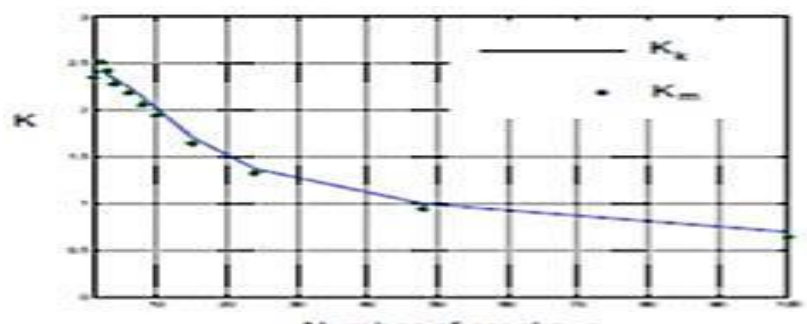

(n) $Y=25, \pi / 2-0,3$

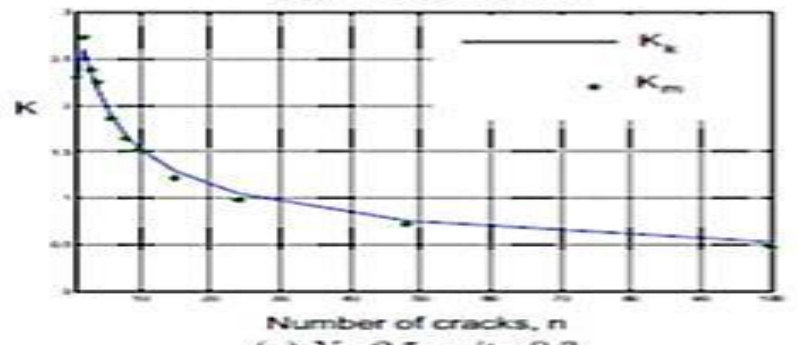

(c) $Y=25,=/ 2=0.3$

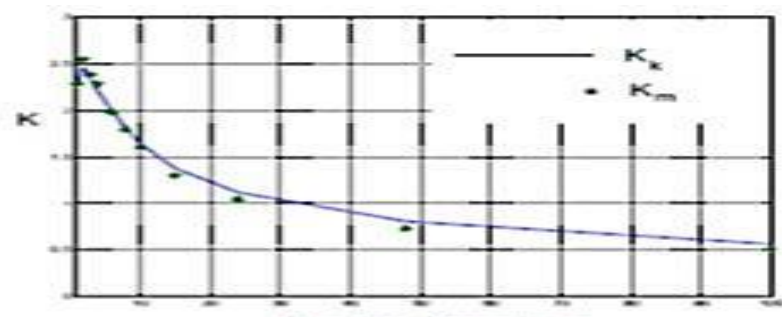

Number of cracks, in

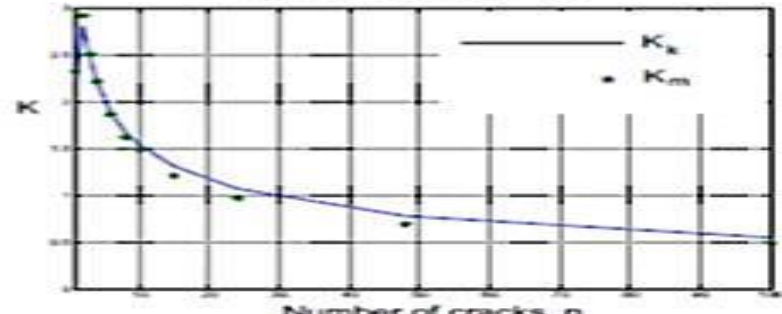

(d) $Y=2.5, a / 2=0.4$

Fig. 12: $K$ Values for $Y=2.5, A / T=0.1$ to $Y=2.5, A / T=0.4$ 


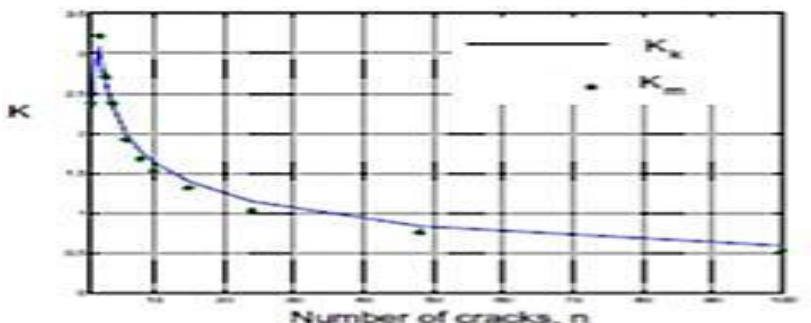

(a) $Y-2,5, x / 2,0.5$

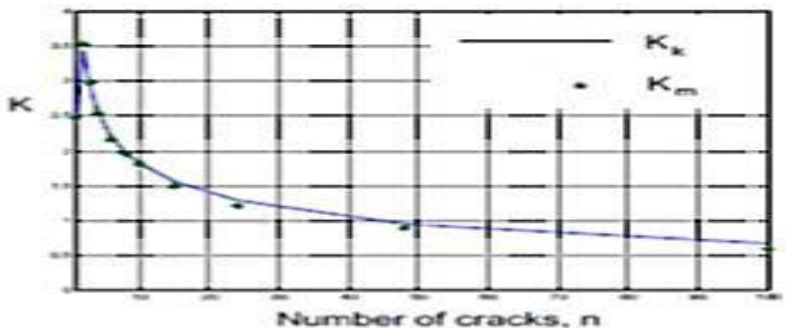

(b) $Y-2.5, m / 2-0.6$

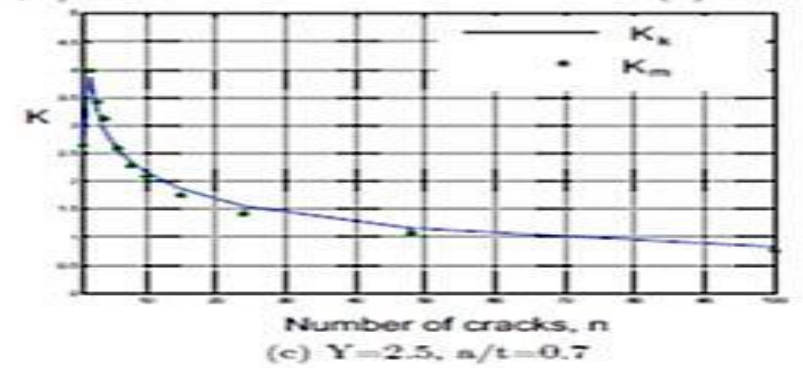

Fig. 13: $K$ Values for $Y=2.5, \mathrm{~A} / \mathrm{T}=0.5$ to $\mathrm{Y}=2.5, \mathrm{~A} / \mathrm{T}=0.7$

The results in Fig. 10(a) and Fig. 10(b) displayed a similar trend with those in Fig. 6. It was however noted that the values of the stress intensity factors in the three Fig. decreased as Y increased. This was because the strength of the cylinders increases with an increasing value of $\mathrm{Y}$.

\section{Conclusion}

The intent of this work was to use the modified virtual crack closure technique to find the SIF in multiply cracked thick walled cylinders. The Ansys14 Finite Element Analysis software was used to get the nodal forces and the nodal displacements near the crack tip. These parameters enabled the purpose of $\mathrm{K}$ values for cylinders with different diameter ratios, crack length to thickness ratio and number of cracks. The solid-Tet-10node-187 elements were used in meshing the models and this was due to their regular agreement around the crack tip that enabled the nodal displacements to be obtained at a constant distance from the crack tip. The models utilized were validated by comparing the finite-element hoop, radial and axial stresses with their equivalent values, which were obtained using Lame's equations. These values were found to be almost identical along the crack face but very unlike at the crack tip due to stress concentration in the surrounding area of the crack tip. Away from the crack tip, the difference between these stresses was less than $3 \%$ in all the cases measured. It was also shown that the modified virtual crack closure technique could not be functional in the analysis of thick walled cylinders in the same way it had been useful in the analysis of at plates. Thus the cracks investigated were assumed to extend by $40 \%$ of the length of the finite element behind the crack tip. In this way, the $\mathrm{K}$ values obtained for cylinders with either single or multiple cracks had an error of less than almost $4 \%$ in most cases. In conclusion, therefore, the $\mathrm{K}$ values obtained for thick walled cylinders were in good agreement with the published results.

\section{References}

[1] CODE, PRESSURE VESSEL. "SECTION VIII, DIVISION." (2010).

[2] Directive, Pressure Equipment. "97/23/EC." Pressure Equipment Directive (PED) (1997).

[3] Asada, Yasuhide. "Japanese Activities Concerning Nuclear Codes and Standards-Part II." Journal of pressure vessel technology 128.1 (2006): 64-70. http://dx.doi.org/10.1115/1.2138063.

[4] Canadian standards association, Boiler, pressure vessel, and pressure piping code. CSA standards, 2009.

[5] Committee ME/1, Un_red pressure vessels Advanced design and construction (Supplement to AS 12101989). Standards Association of Australia, 1990

[6] Germanischer Lloyd, Rules and Guidelines. Germanischer Lloyd, 2009.

[7] Det Norske Veritas, Oil and Gas Processing systems-O shore Standard DNV-OS-E201,Det Norske Veritas, 2008.

[8] Stoomwezen, Rules for pressure vessels. Sdu Publishers, 1997.

[9] Hellan, Kåre. Introduction to fracture mechanics. McGraw-Hill, 1985.

[10] Adldoost, H., A. Zabihollah, and S. J. Fattahi. "Measurement of wall loss in pressure vessels using fbg sensors." (2011): 1-8

[11] Chandwani, Ramesh, Miles Wiehahn, and Chris Timbrell. "3D Fracture mechanics in ANSYS." UK ANSYS conference, Warwickshire, UK. 2004.

[12] www.ecolo.org/archives/archives-nuc-en

[13] Perl, M. "Stress intensity factor approximate formulae for uniform crack arrays in pressurized or autofrettaged cylinders." Engineering fracture mechanics 43.5 (1992): 725-732. http://dx.doi.org/10.1016/0013-7944(92)90003-W.

[14] Goldthorpe, B. D. "Fatigue and fracture of thick walled cylinders and gun barrels." Case Studies in Fracture Mechanics (1977): 77-5.

[15] Clark, G., and M. E. Morton. "Multiple cracking in thick-walled pressure vessels." International Journal of Fracture 15.1 (1979): R17-R20. http://dx.doi.org/10.1007/BF00115916. 
[16] Baratta, Francis I. "Stress intensity factors for internal multiple cracks in thick-walled cylinders stressed by internal pressure using load relief factors." Engineering Fracture Mechanics 10.4 (1978): 691-697. http://dx.doi.org/10.1016/0013-7944(78)90027-9.

[17] Schijve, Jaap. Fatigue of structures and materials. Dordrecht: Kluwer Academic, 2001.

[18] M Thirumump, K Kalita, M Ramachandran and R Ghadai "A numerical study of SCF convergence using ANSYS." ARPN Journal of Engineering and Applied Sciences 10.5 (2015):2233-2238.

[19] K. Kalita, S. Halder. 2014. Static analysis of isotropic and orthotropic plates with central cutout under transverse loading. Journal of Institution of Engineers, Series C, Springer Publications. 95(4): 347-358. http://dx.doi.org/10.1007/s40032-014-0138-9.

[20] Shu, H. M., J. Petit, and G. Bezine. "Stress intensity factors for radial cracks in thick walled cylinders-I. Symmetrical cracks." Engineering fracture mechanics 49.4 (1994): 611-623. http://dx.doi.org/10.1016/0013-7944(94)90053-1.

[21] Shannon, R. W. E. "Stress intensity factors for thick-walled cylinders." International Journal of Pressure Vessels and Piping 2.1 (1974): 19-29. http://dx.doi.org/10.1016/0308-0161(74)90013-1. 